\title{
Test Technology Newsletter
}

\author{
June 2013

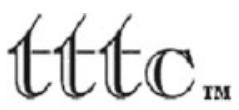 \\ The Newsletter of the Test Technology Technical Council \\ of the IEEE Computer Society
}

Editor: Theo Theocharides

\section{PAST TTTC EVENTS}

\section{1st IEEE VLSI Test Symposium (VTS)}

29 April-2 May, 2013, Berkeley, California, USA

http://www.tttc-vts.org/public_html/new/2013/index.php

The IEEE VLSI Test Symposium (VTS) explores emerging trends and novel concepts in testing, debug and repair of microelectronic circuits and systems.

The VTS Program Committee invited original, unpublished paper submissions for VTS 2013. Paper submissions were to complete manuscripts, up to six pages (inclusive of figures, tables, and bibliography) in a standard IEEE two-column format; papers exceeding the page limit were returned without review. Authors were asked to clearly explain the significance of the work, highlight novel features, and describe the current status.

\section{UPCOMING TTTC EVENTS}

\section{8th IEEE European Test Symposium \\ 27-31 May, 2013, Avignon, France \\ http://www.lirmm.fr/ETS13/}

The IEEE European Test Symposium (ETS) is Europe's premier forum dedicated to presenting and discussing scientific results, emerging ideas, practical applications, hot topics and new trends in the area of electronic-based circuits and system testing.

In 2013 ETS took place in the Congress Center of the Popes' Palace in the beautiful city of Avignon, France.

\section{8th 19th IEEE International On-Line Testing Symposium 8-10 July, 2013, Chania, Crete, Greece \\ http:/tima.imag.fr/conferences/iolts/iolts13/info.php}

Issues related to on-line testing are increasingly important in modern electronic systems. In particular, the huge complexity of electronic systems has led to growth in reliability needs in several application domains as well as pressure for low cost products. There is a corresponding increasing demand for costeffective on-line testing techniques. These needs have increased dramatically with the introduction of very deep submicron and nanometer technologies which adversely impact noise margins, process, voltage and temperature variations, aging and wear-out and make integrating on-line testing and fault tolerance mandatory in many modern ICs. The International OnLine Testing Symposium (IOLTS) is an established forum for presenting novel ideas and experimental data on these areas. The symposium also emphasizes on-line testing in the continuous operation of large applications such as wired, cellular and satellite telecommunication, as well as in secure chips. The Symposium is sponsored by the IEEE Computer Society Test Technology Technical Council and the 2013 edition is organized by the University of Athens, and the TIMA Laboratory.

\section{NEWSLETTER EDITOR'S INVITATION}

I would appreciate input and suggestions about the newsletter from the test community. Please forward your ideas, contributions, and information on awards, conferences, and workshops to Theocharis (Theo) Theocharides, Department of Electrical and Computer Engineering, University of Cyprus, 75 Kallipoleos Avenue, PO Box 20537, Nicosia, 1678, CYPRUS; theocharides@ucy.ac.cy.

Theo Theocharides

Editor, TTTC Newsletter

\section{BECOME A TTTC MEMBER}

For more details and free membership, browse the TTTC Web page: http://tab.computer.org/tttc.

CONTRIBUTIONS TO THIS NEWSLETTER:

Send contributions to Theocharis (Theo) Theocharides, Department of Electrical and Computer Engineering, University of Cyprus, 75 Kallipoleos Avenue, PO Box 20537, Nicosia, 1678, CYPRUS; theocharides@ucy.ac.cy. For more information, see the TTTC Web page: http://tab.computer.org/tttc. 